\title{
Electronic and Physical Studies for Teflon FEP as a Thermal Control in Low Earth Orbit Reinforced With ZnO and SiO2 Nanoparticles
}

Maroof A. Hegazy

NRIAG: National Research Institute of Astronomy and Geophysics

Rasha Ghoneim

NRIAG: National Research Institute of Astronomy and Geophysics

Hend Ezzat

NRIAG: National Research Institute of Astronomy and Geophysics

Ibrahim S. Yahia

King Khaled Univrsity

Hanan Elhaes

Ain Shams University

Medhat IBRAHIM ( $\nabla$ medahmed6@yahoo.com )

NRC, Egypt https://orcid.org/0000-0002-9698-0837

\section{Research Article}

Keywords: Teflon FEP, ZnO, SiO2, DFT, B3LYP/ LAN2DZ, molecular electrostatic potential

Posted Date: August 10th, 2021

DOl: https://doi.org/10.21203/rs.3.rs-707124/v1

License: (c) (i) This work is licensed under a Creative Commons Attribution 4.0 International License. Read Full License 


\section{Abstract}

Fluorinated Ethylene Propylene (Teflon FEP) is used as external layer thermal insulator for Hubble Space Telescope (HST) and on the outside surfaces of space crafts in the low earth orbit (LEO). Teflon FEP was eroding as a result of exposure to Atomic Oxygen (AO) and different electromagnetic waves such as Ultraviolet radiation and X-ray. Model molecules were used to simulate Teflon FEP and its interaction with other nanoparticles such as $\mathrm{ZnO}$ and $\mathrm{SiO}_{2}$. Density functional theory (DFT) was used to calculate model structures using B3LYP/LAN2DZ model. Molecular Electrostatic Potential as contour, band gap energy and total dipole moment were computed for all models. Thermal stability properties were also studied for Teflon FEP both individually and interacted with $\mathrm{ZnO}$ and $\mathrm{SiO}_{2}$. Results showed that a layer of $\mathrm{OZn}$ and $\mathrm{SiO}_{2}$ on Teflon FEP, especially Teflon FEP+OZn+OSiO structure, improves the physical, chemical, thermal, and electrical stability of Teflon FEP, potentially acting as a corrosion-inhibiting layer.

\section{Introduction}

Polymers applied for space applications are now termed as space polymers. Space polymers including Teflon FEP, Kapton polyimide, and poly (methyl methacrylate) can be exposed to a reversal of incident photons, atoms and/or atomic and vacuum ultraviolet (VUV) ions (Moser 2008). Teflon FEP is often used as an external surface of multilayer insulation (MLI) blanket on the Hubble Space Telescope (HST) (Dever 2000; De Groh et al. 2004). Through space shuttle operation missions (SM) to HST, cracks in thickness were found in FEP layers. The material that was sent to Earth for study showed symptoms of significant degradation (De Groh 2003; Minton et al. 2010; Yeong 2017). Aging of Teflon FEP, has also been recorded (Jucius 2011; Jucius et al. 2010, Bhagat 2015). It was found that $\mathrm{Al}_{2} \mathrm{O}_{3}$ atomic layer deposition (ALD) coatings could effectively shield polymers against oxygen-atom erosion and VUV corrosion, because $\mathrm{Al}_{2} \mathrm{O}_{3}$ ALD coatings shield the corresponding polymers from atomic-oxygen attacks (Yeong 2017). Moreover, the modification with $\mathrm{TiO}_{2}$ coatings protects the surfaces from VUV-induced corrosion (Chao 2019). Teflon FEP appears to be very structurally comparable to Polytetrafluoroethylene (PTFE) which is a well-known polymer with remarkable mechanical strength and electrical properties, low impact resistance and thermal stability, as well as other attributes including low surface energy and chemical stability, and is a cost-effective material (Galante 2010). The outstanding mechanical and physicochemical properties of PTFE served as a framework for the addition of $\mathrm{ZnO}$ nanotubes (Shabannia 2014), and enabled for the efficient creation of flexible sensors (Agrawal 2017). The possibility of developing nanoscale photodetectors for nano-optics applications were exhibited for $\mathrm{ZnO}$ nanotubes, which were successfully produced using a wet simple preparation method on such Teflon substrate (Farhat 2015). Silica is a ceramic material with unique properties such as high strength, corrosion inhibition and excellent insulation. Because of these impressive characteristics, $\mathrm{SiO}_{2}$ and PTFE are particularly well suited to a wide range of technical applications. Superhydrophobic structures have shown to be an exceptional asset in variety of applications, including selfcleaning (Plirdpring 2020), and protective properties such as anti-icing (Liang 2018) and anti-corrosion characters (Zhu 2020). Studies on PTFE filled with $\mathrm{SiO}_{2}$ demonstrated that $\mathrm{SiO}_{2}$ filling reduces PTFE porosity deformation while enhancing the material's mechanical properties and toughness (this sentence needs references). Furthermore, it was reported that increasing the quantity of $\mathrm{SiO}_{2}$ increased the 
mechanical strength of PTFE/SiO 2 matrix (Chen 2007). PTFE/SiO 2 /Epoxy composites were also studied (Shen 2015) it was as similar as PANI/PTFE/GO composites, which have registered an improvement in the electrical properties used for the fabrication of electrochemical devices (Badry 2020). $\mathrm{ZnO} / \mathrm{SiO}_{2} /$ PTFE film on glass has been developed with anti-icing characteristics, corrosion resistance and insulation properties, with the film's corrosion resistance and insulating capabilities greatly enhanced owing to the addition of $\mathrm{SiO}_{2}$ medium to the specimen, which gives a new concept for the design of an insulating surface on glass that serves as an anti-icing surface (Ruijin 2017).

Molecular modeling is a series of computational calculations that assess the electronic properties of chemical structures with various interactions by measuring parameters such as HOMO/LUMO band gap energy $(\triangle E)$, total dipole moment (TDM) and molecular electrostatic potential (MESP), that describe the electronic properties and reactivity of the studied structure. DFT: B3LYP/LANL2D is the suitable basis set for studying the matrix of the nanoparticles/polymers interactions (Lee 1988; Miehlich et al. 1989; Becke 1993, Elhaes 2018). Furthermore, Quantitative Structure Activity Relationship (QSAR) is a tool for studying molecular behaviour that may be used to explore the bioactivity and physicochemical properties of novel compounds in the electrical, chemical, and biological sciences (Abdelsalam 2018; Abdelsalam et al. 2019).

The present work is conducted using DFT simulations to assess the electronic properties and thermal stability of Teflon FEP interactions with metal oxides (MOs), such as $\mathrm{ZnO}$ and $\mathrm{SiO}_{2}$. The interaction of Teflon FEP structures with $\mathrm{ZnO}, \mathrm{SiO}_{2}$, and a combined effect of the two MOs was investigated. B3LYP/LANL2DZ was used to calculate TDM, MESP, and $\triangle E$. For the same interactions, QSAR descriptors were developed.

\section{Calculations Details}

Model molecules were designed as four Teflon FEP units. Teflon FEP was then interacted with $\mathrm{ZnO}$ and $\mathrm{SiO}_{2}$. Design and calculations were implemented using the GAUSSIAN09 software at Molecular Spectroscopy and Modeling unit, National Research Centre, Egypt. All model structures were studied using DFT theory at B3LYP level using the LANL2DZ basis set. The values of $\triangle E$, TDM and MESP (as contour) were all calculated using the same level of theory. QSAR descriptors were calculated using semiempirical method at PM6 level of theory.

\section{Result And Discussion}

\subsection{Teflon FEP model structures and HOMO/LUMO orbital distribution:}

The chemical composition of Teflon FEP originally recommended that Teflon FEP gets connected with ZnO through various sites to decide the correct site of interaction of Teflon FEP with MOs, since the interaction of Teflon FEP with other chemical structures and its active sites are unpredictable or unknown. The contact of Teflon FEP with ZnO occurs at numerous sites due to the oxygen atom of ZnO (Ezzat 2019), since MOs interact with other chemical structures through the oxygen atom. As shown in Fig. 1, the optimized structures and their HOMO/LUMO orbital distribution of OZn interaction with Teflon FEP were explored at different 
places (P1, P2, P3, and P4), such that he interaction of OZn with Teflon FEP was simulated as an adsorption state interaction. The main parameters for assessing the electrical properties of materials are TDM and $\triangle \mathrm{E}$. The relationship between the increase in TDM and the decrease in $\triangle \mathrm{E}$ can be used to predict the site through which Teflon FEP should interact with OZn. Table 1 shows that the interaction of Teflon FEP with OZn resulted in a change in the values of TDM which increased from 0.669 to $7.4256,5.4734,5.3226$ and 4.4706 Debye for Teflon FEP + OZn (P1, P2, P3 and P4) respectively, while $\triangle E$ decreased from 7.4391 to 2.3043 , 2.2134, 1.7799 and $2.2466 \mathrm{eV}$ for Teflon FEP + OZn for P1, P2, P3 and P4 respectively. The lowest value of $\triangle E$ was recorded for Teflon FEP $+\mathrm{OZn}$ P3 which, therefore, represents the most suitable position of interaction for Teflon FEP.

Table 1

DFT:B3LYP/LANL2DZ calculations for Teflon FEP and Teflon FEP interaction with OZn through different sites of Teflon FEP structure as TDM (Debye) and $\Delta \mathrm{E}(\mathrm{eV})$.

\begin{tabular}{|lll|}
\hline Structure & TDM & $\Delta \mathrm{E}$ \\
\hline Teflon FEP & 0.669 & 7.4391 \\
\hline Teflon FEP + OZn P1 & 7.4256 & 2.3043 \\
\hline Teflon FEP + OZn P2 & 5.4734 & 2.2134 \\
\hline Teflon FEP + OZn P3 & 5.3226 & 1.7799 \\
\hline Teflon FEP + OZn P4 & 4.4706 & 2.2466 \\
\hline
\end{tabular}

Accordingly, 4 units of Teflon FEP were interacted with $4 \mathrm{ZnO}, \mathrm{SiO}_{2}$ and a combination of the $\mathrm{ZnO}$ and $\mathrm{SiO}_{2}$. In the case of the interaction of a combination of $\mathrm{ZnO}$ and $\mathrm{SiO}_{2}$ with Teflon FEP, the interaction was supposed to happen as sandwich; once as Teflon FEP $+40 Z n+40 S i O$ and once as Teflon FEP + 4OSiO + $40 \mathrm{Zn}$, and other as $\mathrm{ZnO}$ and $\mathrm{SiO}_{2}$ together interacted with Teflon FEP atom by atom (Teflon FEP + 4OZn/4OSiO) as illustrated in Fig. 2. TDM and $\triangle E$ were calculated for the different proposed types of interaction. TDM increased from 0.669 Debye of Teflon FEP alone to 7.4534, 21.2799, 12.2910, 13.2651 and 5.7131 Debye for Teflon FEP + 4ZnO, Teflon FEP + 4OSiO, Teflon FEP + 4OZn + 4OSiO, Teflon FEP + 4OSiO + $40 Z n$, and Teflon FEP $+40 Z n / 40 S i O$ respectively as illustrated in Table 2. Moreover, $\triangle E$ decreased for the same structures from 7.439 to $0.5200,0.5007,0.2195,0.5606$ and $0.3135 \mathrm{eV}$ respectively. The lowest value of $\Delta \mathrm{E}$ observed was for Teflon FEP $+4 \mathrm{OZ} \mathrm{n}+4 \mathrm{OSiO}$ which is an indication for the most probable interaction to occur, which enhanced the electrical properties of the Teflon FEP. 
Table 2

DFT:B3LYP/LANL2DZ calculations as TDM (Debye) and band gap energy $\triangle \mathrm{E}(\mathrm{eV})$ for Teflon FEP and

Teflon FEP interacted with $4 \mathrm{ZnO}, \mathrm{SiO}_{2}$ and a combination of the two MOs.

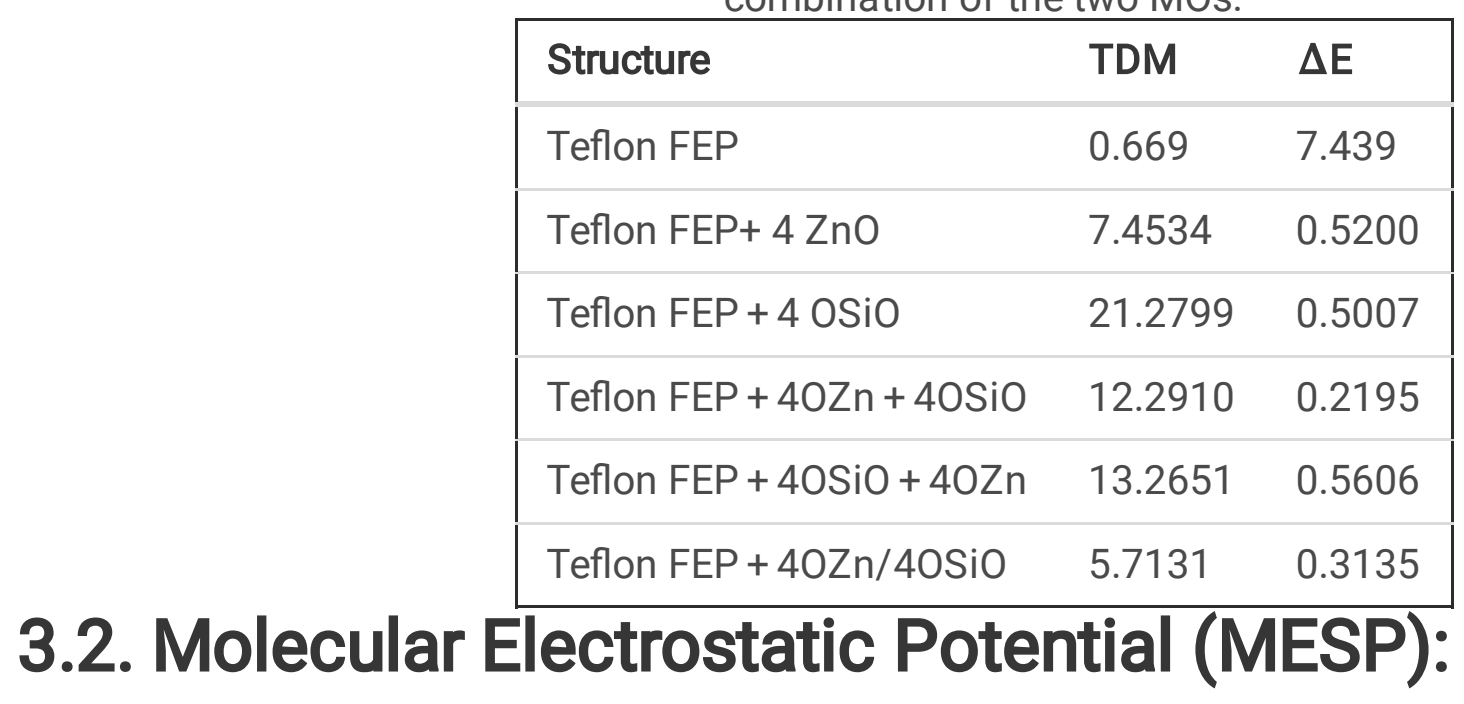

In order to evaluate the interaction identity of nucleophilicity, MESP was investigated using LANL2DZ basis set for the implemented Teflon FEP structure using the DFT method. The MESP maps for Teflon FEP, Teflon $\mathrm{FEP}+4 \mathrm{ZnO}$, Teflon FEP + 40SiO, Teflon FEP + 4OZn + 40SiO, Teflon FEP + 40SiO + 4OZn, and Teflon FEP + $40 Z n / 40 S i O$ are shown in Fig. 3. The MESP maps show the calculation of neighbouring charges, nucleus and electron concentration at a given location. The MESP map is classified as red $<$ orange $<$ yellow $<$ green $<$ blue. The colour difference in the MESP map, which is red, indicates the lowest MESP level while blue indicates reaching the maximum MESP value. As shown in Fig. 3, the MESP maps for all connections appear coloured with intermediate colours between red and blue, which represents less electrostatic repulsion and indicates that there is still no possibility of interacting with other chemical structures, thus reflecting more chemical stability.

\subsection{Quantitative Structure Activity Relationship (QSAR):}

QSAR descriptors total energy (TE), heat of formation (HF), ionization potential (IP), logarithm of the partition coefficient $(\log P)$, polarization, molar refractivity (MR) and molecular weight (MW) were calculated for Teflon FEP and Teflon FEP interactions with $\mathrm{MO}$ as Teflon FEP $+4 \mathrm{ZnO}$, Teflon FEP + 4 OSiO, Teflon FEP + 4OZn+40SiO, Teflon FEP + 40SiO, Teflon FEP + 4OSiO + 4OZn and Teflon FEP + 4OZn as shown in Table 3 . $T E$ is reported to characterize the stability upon the mechanism but whenever TE decreases, the structure is described as more durable. TE values of Teflon FEP $+4 Z n O$, Teflon FEP $+40 S i O$, Teflon FEP $+40 S i O$, Teflon $\mathrm{FEP}+4 \mathrm{OZn}+4 \mathrm{OSiO}$, Teflon FEP + 40SiO + 40Zn and Teflon FEP + 40Zn/4OSiO were - 21251.090, $-22705.140,-24230.924,-25747.075,-25709.596$ and $-23487.043 \mathrm{eV}$ respectively, indicating very stable structures.

$\mathrm{HF}$ is a fundamental thermal descriptor that represents the energy generated as heat when atoms, existing at theoretically infinite distances, connect and build a molecule. Although HF is a concern, it could be explained by the variation in enthalpy during the creation of a single mole of a material from its components in its normal and complete equilibrium under standard atmospheric conditions at a particular temperature. HF 
values for Teflon FEP + 4ZnO, Teflon FEP + 40SiO, Teflon FEP + 40SiO, Teflon FEP + 40Zn + 40SiO, Teflon $\mathrm{FEP}+40 \mathrm{SiO}+4 \mathrm{OZn}$ and Teflon FEP + 40Zn/4OSiO were - 1570.764, -1838.877, -2292.065, -2726.749, -2488.378 and -2042.500 respectively, reflecting the production of a small amount of energy for Teflon FEP $+40 \mathrm{Zn}+40 \mathrm{SiO}$.

The following descriptor is the IP which characterizes the reactivity of the compound and is defined as the energy required for the compound to also be ionized, meaning that the lower the IP value, the higher the reactivity of such compound. Results indicated no significant differentiation between the IP values that measured - 12.980, -9.759, -11.684, -9.450, -11.074 and - 9.851 for Teflon FEP, Teflon FEP + 4 ZnO, Teflon FEP + 4 OSiO, Teflon FEP + 4OZn + 40SiO, Teflon FEP + 40SiO + 40Zn and Teflon FEP + 40Zn/40SiO respectively. The increased IP values confirm that the reactivity of the new structures is quite low, with the lowest reactivity obtained was for Teflon FEP + 40Zn + 40SiO.

Log $P$ is a definition of the hydrophilicity of the chemical substance. Log $P$ is the ratio of the concentration of a substance dissolved in, for example, an organic solution to its concentration dissolved in an aqueous solvent at equilibrium. As a consequence, positive log $\mathrm{P}$ values are corresponding to hydrophobic compounds, while negative values are corresponding to hydrophilic compounds. All suggested models resulted in positive log $P$ values, indicating that the compounds are hydrophobic, chemically soluble and are not affected by the surrounding medium.

The final QSAR descriptor is polarizability which is described as a basic property that defines how the chemical structure could be polarized in response to variation forces, which reflects the reactivity of the structures influenced by their volume. In fact, MR is a descriptor which determines the total polarization of a mole of the substance, such that the higher the molar refractivity, the higher the reactivity of the substance.

The obtained results support the theory that a layer of $\mathrm{OZn}$ and $\mathrm{SiO}_{2}$ on Teflon FEP, in the form of Teflon FEP + OZn + OSiO, improves the physical, chemical, thermal, and electrical stability of Teflon FEP, which might serve as a corrosion-inhibiting layer for Teflon FEP that is prone to corrosion during space missions. 
Table 3

QSAR descriptors as Total Energy (eV), Heat of formation (HF), lonization potential (eV), Log P, Polarizability, Molar refractive (MR), molecular weight (MW) calculated at PM6 level for Teflon FEP and Teflon FEP interacted with $4 \mathrm{ZnO}, 4 \mathrm{SiO} 2$ and a combination of both MOs.

\begin{tabular}{|c|c|c|c|c|c|c|c|}
\hline Sample & TE & HF & IP & $\log P$ & Polarizability & MR & MW \\
\hline Teflon FEP & -21251.090 & -1969.435 & -13.328 & 12.801 & 28.228 & 1002.166 & 802.136 \\
\hline $\begin{array}{l}\text { Teflon FEP + } \\
40 Z n\end{array}$ & -22705.140 & -1838.877 & -9.759 & 11.396 & 53.506 & 1327.800 & 1327.800 \\
\hline $\begin{array}{l}\text { Teflon FEP + } \\
40 \text { SiO }\end{array}$ & -24230.924 & -2292.065 & -11.684 & 9.990 & 44.738 & 1242.503 & 1242.503 \\
\hline $\begin{array}{l}\text { TeflonFEP + } \\
40 \mathrm{Zn}+ \\
40 \mathrm{SiO}\end{array}$ & -25747.075 & -2726.749 & -9.450 & 8.584 & 55.772 & 1568.137 & 1568.137 \\
\hline $\begin{array}{l}\text { TeflonFEP + } \\
40 \mathrm{SiO}+ \\
40 \mathrm{Zn}\end{array}$ & -25709.596 & -2488.378 & -11.074 & 8.584 & 58.688 & 1568.137 & 1568.137 \\
\hline $\begin{array}{l}\text { Teflon FEP + } \\
40 Z n / 40 S i O\end{array}$ & -23487.043 & -2042.500 & -9.851 & 10.693 & 46.500 & 1285.151 & 1285.151 \\
\hline
\end{tabular}

\section{Conclusion}

Molecular modelling at DFT level using B3LYP/LAN2DZ basis set can be efficiently applied to investigate the changes in the electronic behavior of the model molecules representing Teflon FEP and Teflon FEP interacted with nanoparticles of $\mathrm{ZnO}, \mathrm{SiO}_{2}$, and a combination of both $\mathrm{MOs}$. The numerous parameters studied for all the proposed structures, including the $\triangle \mathrm{E}, \mathrm{MESP}$ as a contour, and even the thermal stability properties reflected by QSAR descriptors indicated that the interaction between Teflon FEP and MOs showed that a coating of $\mathrm{OZn}$ and $\mathrm{SiO}_{2}$ on Teflon FEP, in the form of Teflon FEP + OZn + OSiO, increases the stability of all the properties under investigation, thus qualifying this coating to be a potential upgrade for Teflon FEP as a corrosion-inhibiting layer for space missions.

\section{Declarations}

\section{Acknowledgements}

The authors extend their appreciation to the Scientific Research Deanship at King Khalid University and the Ministry of Education in KSA for funding this research work through the project number IFP-KKU-2020/10.

Funding: (King Khalid University and the Ministry of Education in KSA for funding this research work through the project number IFP-KKU-2020/10)

Conflicts of interest/Competing interest: (N/A)

Availability of data and material: (N/A) 
Code availability: (N/A)

Authors' contributions: (Dr. Maroof A. Hegazy wrote the result and discussion, Dr. Rasha Ghoneim wrote the introduction of the manuscript, Hend A. Ezzat calculated the model structures, Prof. Ibrahim S. Yahia revised the manuscript, Prof. Hanan Elhaes contribute in the result and discussion writing, and Prof. Medhat A. Ibrahim revised the manuscript and submitted it for publication)

\section{References}

1. Agrawal N, Munjal S, Ansari MZ, Khare N (2017) Superhydrophobic palmitic acid modified ZnO nanoparticles. Ceram Int 43:14271-14276

2. Abdelsalam H, Saroka VA, Ali M, Teleb NH, Elhaes H, Ibrahim MA (2019) Stability and electronic properties of edge functionalized silicene quantum dots: A first principles study. Physica E Low Dimens Syst Nanostruct 108:339-346

3. Abdelsalam H, Elhaes $\mathrm{H}$, Ibrahim MA (2018) Tuning electronic properties in graphene quantum dots by chemical functionalization: Density functional theory calculations. Chem Phys Lett 695:138-148

4. Abdelsalam $H$, Elhaes $H$, Ibrahim MA (2018) First principles study of edge carboxylated graphene quantum dots. Physica B 537:77-86

5. Bhagat SD, Gupta MC (2015) Superhydrophobic microtextured polycarbonate surfaces. Surf Coat Technol 270:117-122

6. Badry R, Radwan SH, Ezzat D, Ezzat H, Elhaes H, Ibrahim M (2020) Study of the Electronic Properties of Graphene Oxide/(PANi/Teflon). Biointerface Res Appl 10:6926-6935

7. Badry R, Ghanem ASA-E, Ahmed H, Fahmy A, Elhaes H, Refaat A, Ibrahim M (2018) Effect of Li, Na, K, Be, $\mathrm{Mg}$ and $\mathrm{Ca}$ on the electronic properties, geometrical parameters of carboxylic acids. Biointerface Res Appl Chem 8:3657-3660

8. Becke AD (1993) Density-functional thermochemistry. III. The role of exact exchange. J Chem Phys 98:5648-5652

9. Chao M, Guo C, Feng A, Huang Z, Yang Q, Wu G (2019) Improved Thermal Conductivity and Mechanical Property of PTFE Reinforced with Al203. Nano 14:1950064

10. Chen XM, Liu KW, Yang QF (2007) Study on prepartion and mechanical properties of PTFE/nano-SiO 2 composites. Chemical Research Application 19:831

11. Dever JA, De Groh KK, Banks BA (2000) Environmental Exposure Conditions for Teflon ${ }^{\circledR}$ Fluorinated Ethylene Propylene on the Hubble Space Telescope. High Perform Polym 12:125-139

12. De Groh KK, Martin M (2004) Thermal Contributions to the Degradation of Ground Laboratory and Space-Irradiated Teflon. J Spacecr Rockets 41:366-372

13. De Groh KK, Martin M: Thermal Contributions to the Degradation of Ground-Laboratory-and SpaceIrradiated Teflon Investigated. (2003)

14. Ezzat H, Badry R, Yahia IS, Zahran HY, Elhaes H, Ibrahim MA (2018) Mapping the molecular electrostatic potential of carbon nanotubes. Biointerface Res Appl 8:3539-3542 
15. Elhaes H, Ezzat H, Morsy M, El-Khodary SA, Yahia IS, Zahran HY, Ibrahim MA (2018) PVC/ZnO NanoComposite as Gas Sensor for Natural Gas. Sensor Lett 16:513-516

16. Ezzat HA, Hegazy MA, Nada NA, Ibrahim MA (2019) Effect of Nano Metal Oxides on the Electronic Properties of Cellulose, Chitosan and Sodium Alginate. Biointerface Res Appl Chem 9:4143-4149

17. Farhat OF, Halim MM, Abdullah MJ, Ali MKM, Ahmed NM, Allam NK (2015) Growth of vertically aligned ZnO nanorods on Teflon as a novel substrate for low-power flexible light sensors. Appl Phys A 119:1197-1201

18. Frisch MJ et al, Gaussian 09 Revision C.01, Gaussian Inc., Wallingford CT, (2010)

19. Galante AMS, Galante OL, Campos LL: Study on application of PTFE, FEP and PFA fluoropolymers on radiation dosimetry, Nuclear Instruments and Methods in Physics Research Section A: Accelerators, Spectrometers, Detectors and Associated Equipment. 619, 177-180 (2010)

20. Hansch C, Leo L (1995) Exploring QSAR: fundamentals and applications in chemistry and biology. American Chemical Society, Washington

21. Ibrahim M, El-Haes H (2005) Computational Spectroscopic Study of Copper, Cadmium, Lead and Zinc Interactions in the Environment. Int J Environ Pollut 23:417-424

22. Ibrahim M (2009) Molecular Modelling and FTIR Study for K, Na, Ca and Mg Coordination with Organic Acid. J Comput Theor Nanosci 6:682-685

23. Ibrahim M, Mahmoud A-A (2009) Computational Notes on the Reactivity of some Functional Groups. J Comput Theor Nanosci 6:1523-1526

24. Jucius D, Grigaliūnas V, Mikolajūnas M, Guobienė A, Kopustinskas V, Gudonytè A, Narmontas P (2011) Hot embossing of PTFE: towards superhydrophobic surfaces. Appl Surf Sci 257:2353-2360

25. Jucius D, Guobienè A, Grigaliūnas V (2010) Surface texturing of polytetrafluoroethylene by hot embossing. Appl Surf Sci 256:2164-2169

26. Liang Y, Ju J, Deng N, Zhou X, Yan J, Kang W, Cheng B (2018) Super-hydrophobic self-cleaning bead-like $\mathrm{SiO}_{2} @$ PTFE nanofiber membranes for waterproof-breathable applications. Appl Surf Sci 442:54-64

27. Lee C, Yang W, Parr RG (1988) Development of the Colic-Salvetti correlation-energy formula into a functional of the electron density. Phys Rev B 37:785

28. Moser M, Semprimoschnig COA, Van Eesbeek MRJ, Pippan R (2008) Surface and Bulk Degradation of Teflon ${ }^{\circledR}$ FEP Retrieved from the Hubble Space Telescope Solar Arrays. High Perform Polym 20:429-446

29. Minton TK, Wu B, Zhang J, Lindholm NF, Abdulagatov Al, O’Patchen J, Groner MD (2010) Protecting polymers in space with atomic layer deposition coatings. ACS Appl Mater Interfaces 2:2515-2520

30. Miehlich B, Savin A, Stoll H, Preuss H (1989) Results obtained with the correlation energy density functionals of Becke and Lee, Yang and Parr. Chem Phys Lett 157:200-206

31. Plirdpring T, Neamsong P, Prachachet R, Chananonnawathorn C, Lertvanithphol T, Pattantsetakul V, Horprathum M: Preparation of PTFE-coated $\mathrm{SiO}_{2}$ nanorod films for self-cleaning application. In AIP Conference Proceedings. AIP Publishing LLC. 2279, 120005 (2020)

32. Politzer P, Laurence PR, Jayasuriya K (1985) Molecular electrostatic potentials: an effective tool for the elucidation of biochemical phenomena. Environ Health Perspect 61:191-202 
33. Ruijin L, Chao L, Yuan Y, Yizheng D, Aoyun Zh (2017) Anti-icing performance of $\mathrm{ZnO} / \mathrm{SiO}_{2} / \mathrm{PTFE}$ sandwich-nanostructure superhydrophobic film on glass prepared via RF magnetron sputtering. Mater Lett 206:109-112

34. Shabannia R, Abu Hassan H (2014) Controllable vertically aligned ZnO nanorods on flexible polyethylene naphthalate (PEN) substrate using chemical bath deposition synthesis. Appl Phys A 114:579-584

35. Shen JT, Top M, Pei YT, De Hosson JTM (2015) Wear and friction performance of PTFE filled epoxy composites with a high concentration of $\mathrm{SiO} 2$ particles. Wear 322:171-180

36. Welsh WJ, Tong W (2007) In: Ekins S (ed) Georgopoulos PG Toxicoinformatics: an introduction in: computational toxicology: risk assessment for pharmaceutical and environmental chemicals. John Wiley \& Sons, Inc., New Jersey, pp 151-181

37. Yeong YH, Gupta MC (2017) Hot embossed micro-textured thin superhydrophobic Teflon FEP sheets for low ice adhesion. Surf Coat Technol 313:17-23

38. Yeong YH, Gupta MC (2017) Hot embossed micro-textured thin superhydrophobic Teflon FEP sheets for low ice adhesion. Surf Coat Technol 313:17-23

39. Zhu X, Feng S, Zhao S, Zhang F, Xu C, Hu M, Zhong Z, Xing W (2020) Perfluorinated superhydrophobic and oleophobic $\mathrm{SiO}_{2} @$ PTFE nanofiber membrane with hierarchical nanostructures for oily fume purification. J Membr Sci 594:117473

\section{Figures}


20,

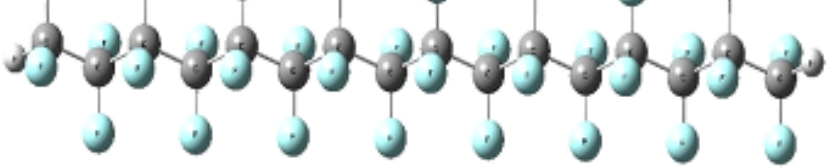

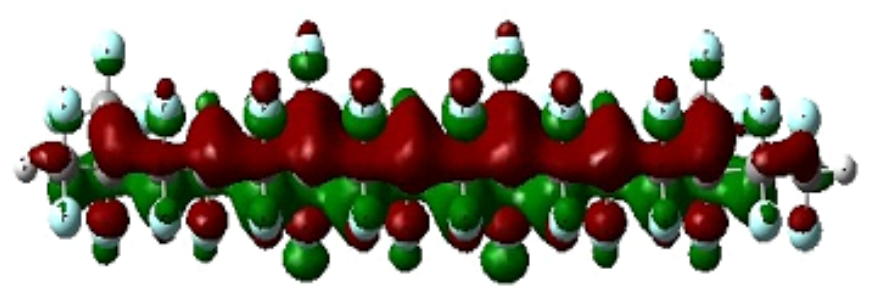

(a)

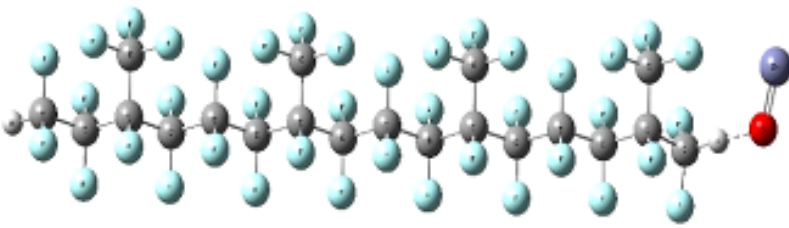

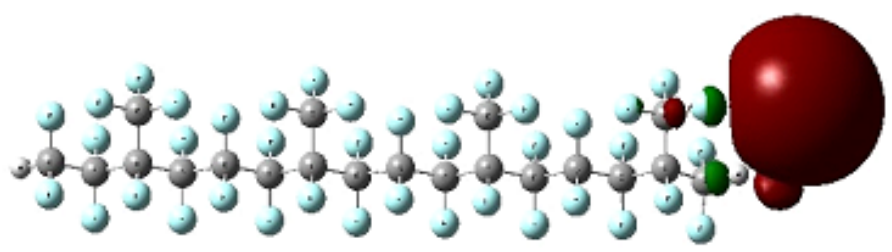

(b)

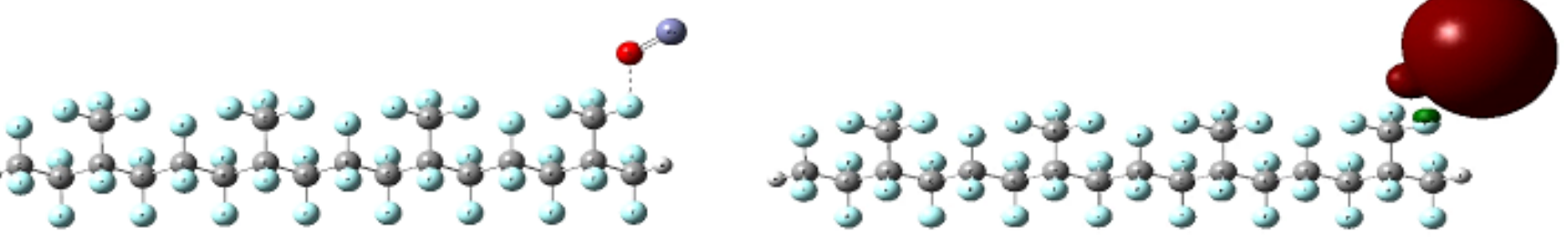

(c)

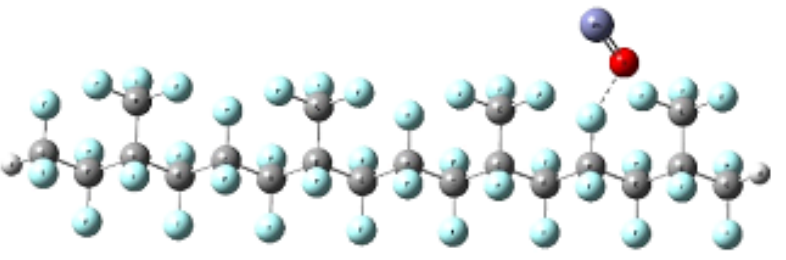

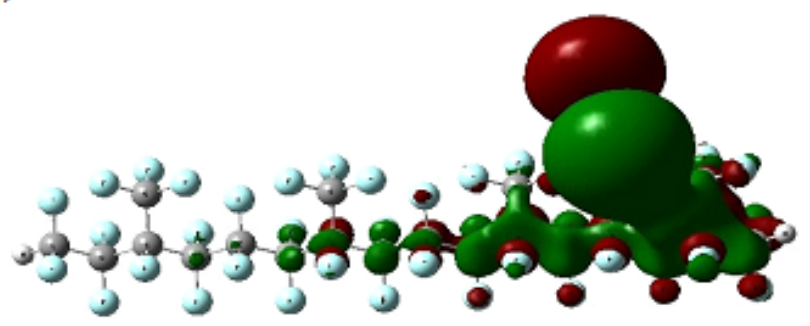

(d)
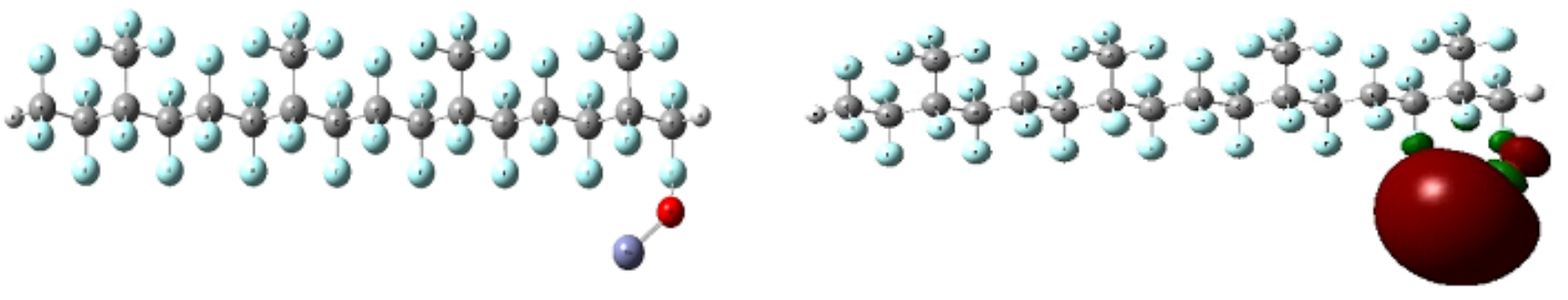

(e)

\section{Figure 1}

Optimized and HOMO/LUMO orbital distribution of Teflon FEP and Teflon FEP with MOs such as OZn as (a) Teflon FEP; (b) Teflon FEP+OZn P1; (c) Teflon FEP+OZn P2; (d) Teflon FEP+OZn P3; (e) Teflon FEP+OZn P4 

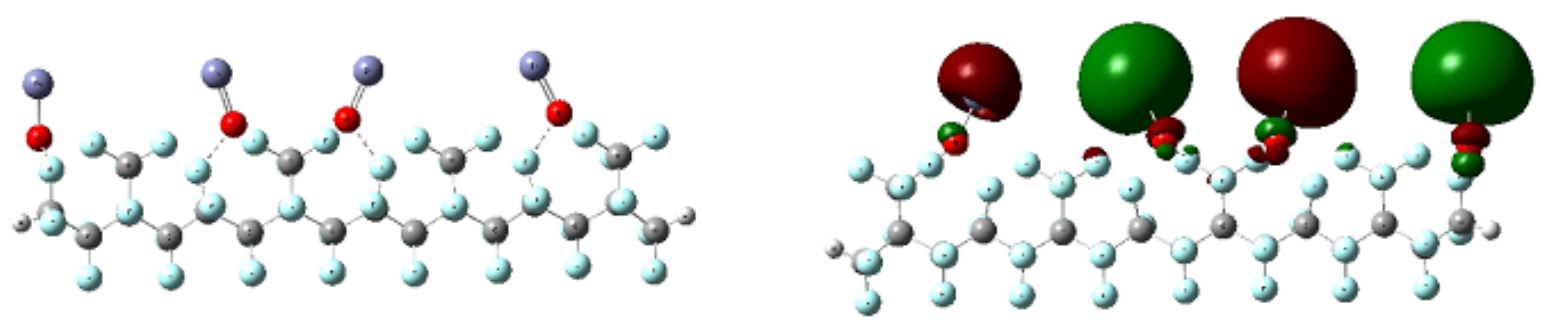

(a)
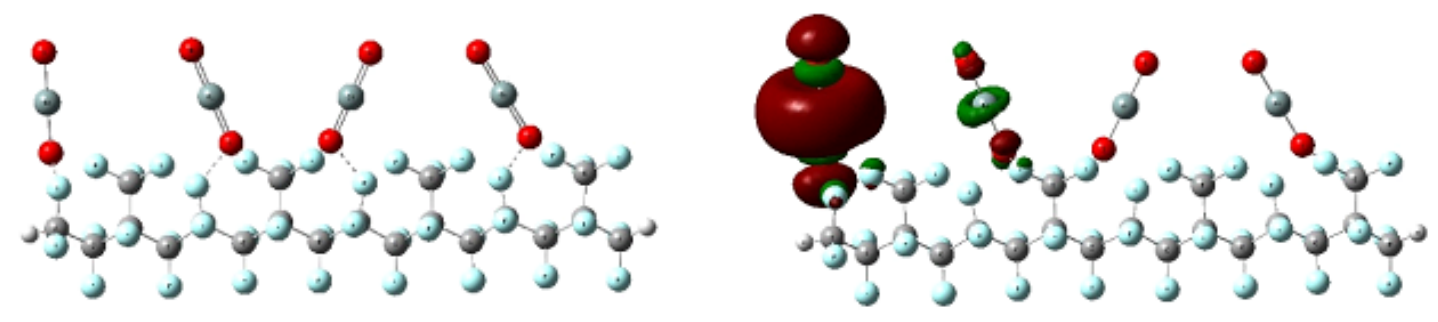

(b)
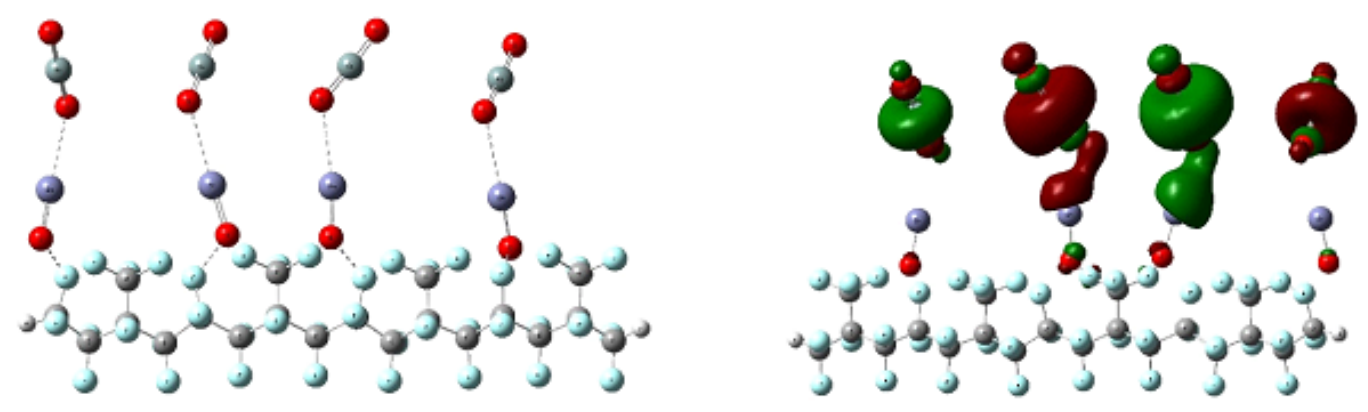

(c)
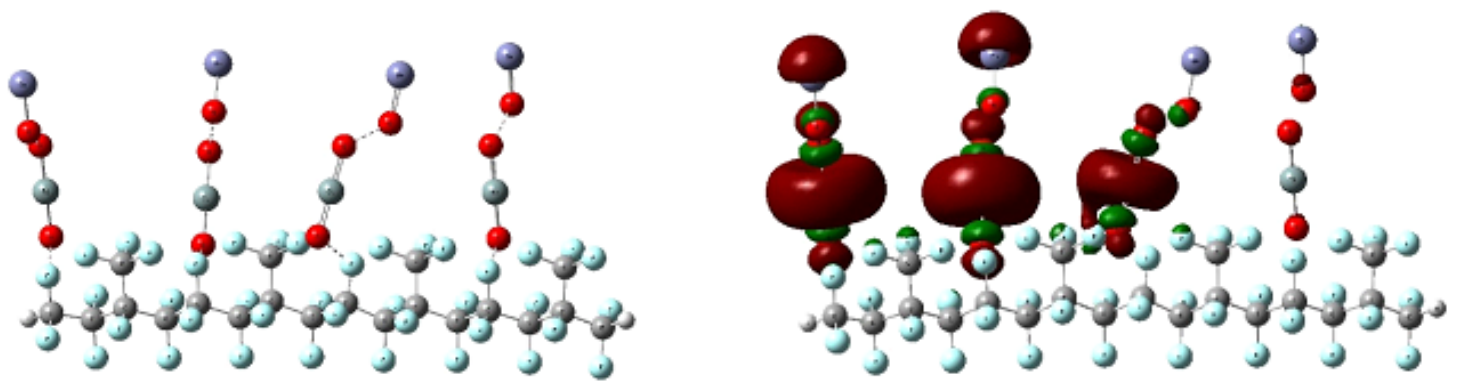

(d)

Figure 2

Optimized and HOMO/LUMO orbital distribution of Teflon FEP and Teflon FEP interaction with $4 \mathrm{ZnO}$, SiO2 and a combination of the two MOs. (a) Teflon FEP; (b) Teflon FEP+4OZn; (c) Teflon FEP+4 OSiO; (d) Teflon FEP+4OZn+4OSiO; (e) Teflon FEP+4OSiO+4OZn; (f) Teflon FEP+4OZn/4OSiO 


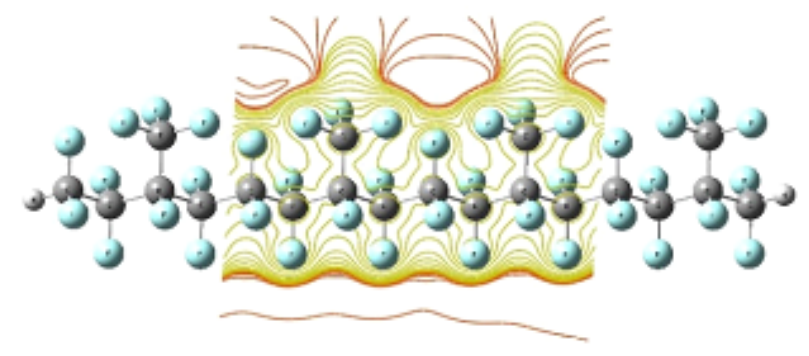

(a)

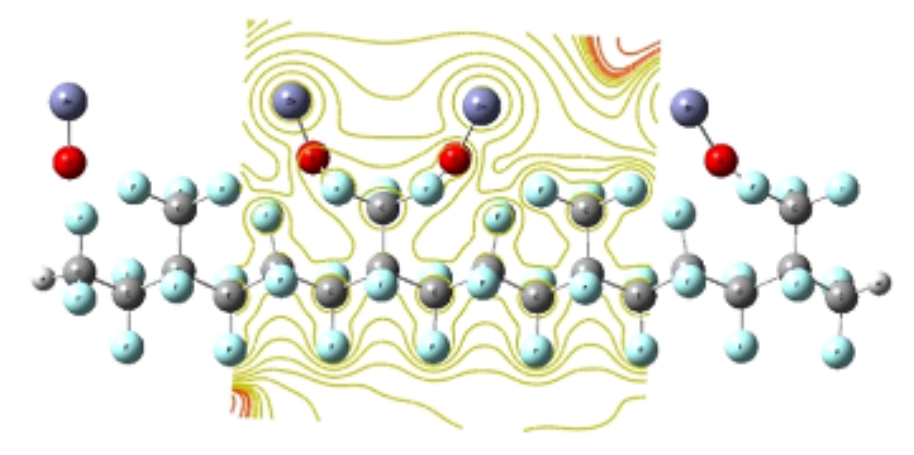

(b)

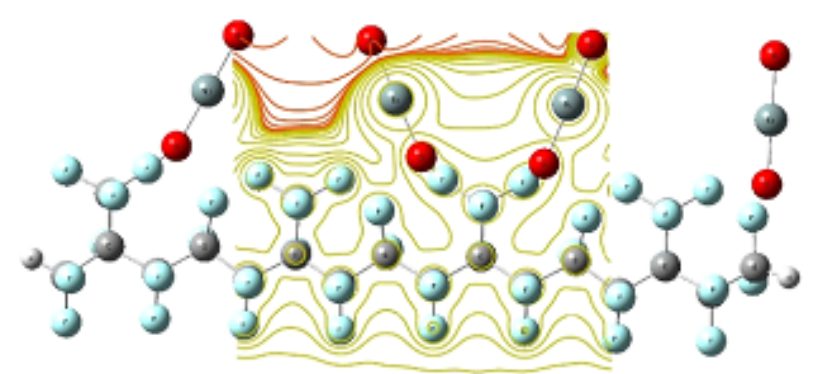

(c)

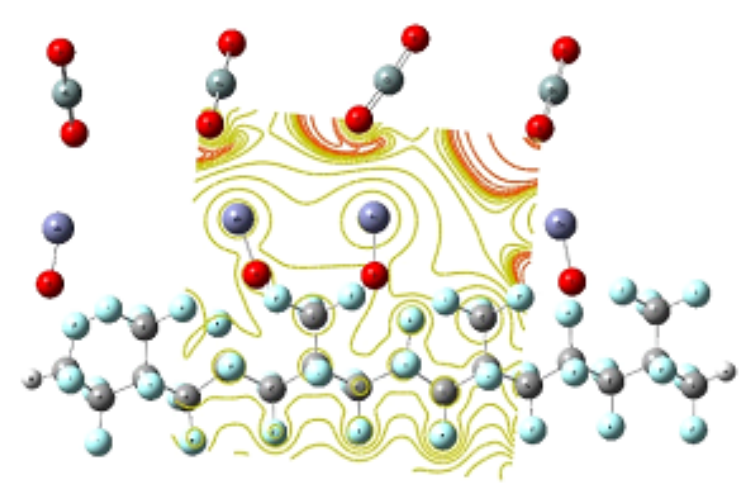

(d)

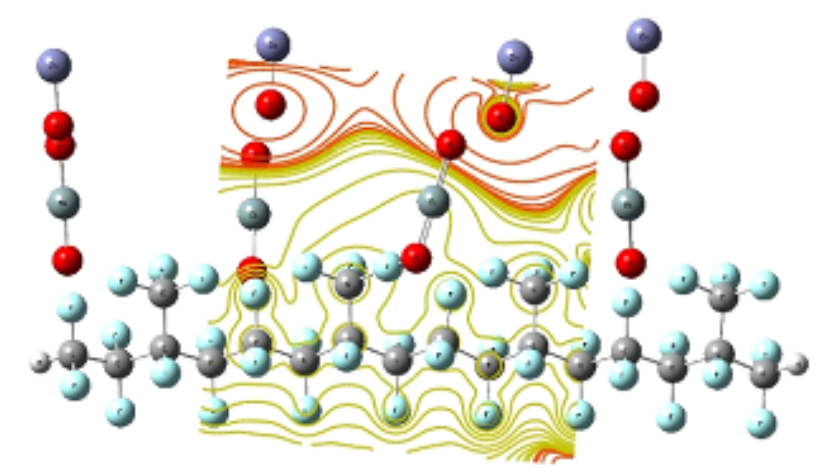

(e)

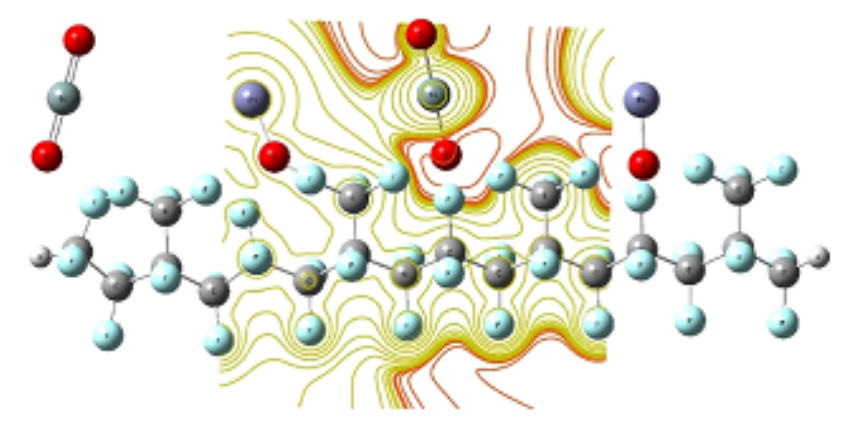

(f)

\section{Figure 3}

Teflon FEP and Teflon FEP interaction with $\mathrm{ZnO}$, SiO2 and a combination between the two MOs together MESP as (a) Teflon FEP; (b) Teflon FEP+4 OZn; (c) Teflon FEP+40SiO; (d) Teflon FEP+4OZn+40SiO; (e) Teflon FEP+40SiO+40Zn; (f) Teflon FEP+40Zn/40SiO 